\title{
A schizophrenia-associated HLA locus affects thalamus volume and asymmetry
}

\author{
Nicolas Brucato $^{\mathrm{a}, \mathrm{b}, *}$, Tulio Guadalupe ${ }^{\mathrm{a}, \mathrm{c}}$, Barbara Franke ${ }^{\mathrm{d}, \mathrm{e}, \mathrm{f}}$, Simon E. Fisher ${ }^{\mathrm{a}, \mathrm{g}}$, Clyde Francks $^{\mathrm{a}, \mathrm{g}}$ \\ a Language \&' Genetics Department, Max Planck Institute for Psycholinguistics, Nijmegen, The Netherlands \\ ${ }^{\mathrm{b}}$ Leiden University Centre for Linguistics, Leiden, The Netherlands \\ ${ }^{\mathrm{C}}$ International Max Planck Research School for Language Sciences, Max Planck Institute for Psycholinguistics, Nijmegen, The Netherlands \\ ${ }^{\mathrm{d}}$ Department of Human Genetics, Radboud University Nijmegen Medical Center, Nijmegen, The Netherlands \\ e Department of Psychiatry, Donders Institute for Brain, Cognition and Behaviour, Radboud University Nijmegen Medical Center, Nijmegen, The Netherlands \\ ${ }_{\mathrm{f}}^{\mathrm{f}}$ Department of Cognitive Neuroscience, Donders Institute for Brain, Cognition and Behaviour, Radboud University Nijmegen Medical Center, Nijmegen, The Netherlands \\ ${ }^{\mathrm{g}}$ Donders Institute for Brain, Cognition and Behavior, Radboud University Nijmegen, The Netherlands
}

\section{A R T I C L E I N F O}

\section{Article history:}

Received 14 November 2014

Received in revised form 20 January 2015

Accepted 7 February 2015

Available online 26 February 2015

\section{Keywords:}

Brain imaging genetics

Psychiatry

Thalamus

Hippocampus

Laterality

HLA

$\mathrm{MHC}$

\begin{abstract}
A B S T R A C T
Genes of the Major Histocompatibility Complex (MHC) have recently been shown to have neuronal functions in the thalamus and hippocampus. Common genetic variants in the Human Leukocyte Antigens (HLA) region, human homologue of the MHC locus, are associated with small effects on susceptibility to schizophrenia, while volumetric changes of the thalamus and hippocampus have also been linked to schizophrenia. We therefore investigated whether common variants of the HLA would affect volumetric variation of the thalamus and hippocampus. We analysed thalamus and hippocampus volumes, as measured using structural magnetic resonance imaging, in 1.265 healthy participants. These participants had also been genotyped using genome-wide single nucleotide polymorphism (SNP) arrays. We imputed genotypes for single nucleotide polymorphisms at high density across the HLA locus, as well as HLA allotypes and HLA amino acids, by use of a reference population dataset that was specifically targeted to the HLA region. We detected a significant association of the SNP rs17194174 with thalamus volume (nominal $P=0.0000017$, corrected $P=0.0039$ ), as well as additional SNPs within the same region of linkage disequilibrium. This effect was largely lateralized to the left thalamus and is localized within a genomic region previously associated with schizophrenia. The associated SNPs are also clustered within a potential regulatory element, and a region of linkage disequilibrium that spans genes expressed in the thalamus, including $H L A-A$. Our data indicate that genetic variation within the HLA region influences the volume and asymmetry of the human thalamus. The molecular mechanisms underlying this association may relate to HLA influences on susceptibility to schizophrenia.
\end{abstract}

(c) 2015 Elsevier Inc. All rights reserved.

\section{Introduction}

Schizophrenia is a severe disorder that is often characterized by auditory and visual hallucinations (DSM-5) (American Psychiatric Association, 2013). Susceptibility arises in part from multiple small effects of genetic variants which are common in the population (Purcell et al., 2014). Among the significant genetic associations found with schizophrenia by genome-wide association scans (GWAS), those within the Human Leukocyte Antigens (HLA) region, on chromosome $6 \mathrm{p}$, are of particular interest because they hint at a role of immunological genes in disease pathogenesis (Andreassen

* Corresponding author at: Leiden University Centre for Linguistics (LUCL), P.O. Box 9515, NL-2300 RA Leiden, The Netherlands. Tel.: +31 715274129.

E-mail address: n.g.a.brucato@hum.leidenuniv.nl (N. Brucato). et al., 2014; McAllister, 2014; Stringer et al., 2014). The HLA region, the human homologue of the Major Histocompatibility Complex (MHC) region, spans about 4.5 million base pairs containing more than 200 genes, many of them involved in the immune system, such as those coding for the HLA proteins (Cullen et al., 2002; Shiina et al., 2009).

Associations with schizophrenia, of polymorphisms within the HLA region, have been found at broadly three different locations in the region (see Fig. 1): two SNPs between HLA-DRA and HLADQA1 (Ripke et al., 2013; Shi et al., 2009); one locus at NOTCH4 (Stefansson et al., 2009); and a cluster of findings between ZNRD1 and TRIM26 (Cross-Disorder Group of the Psychiatric Genomics Consortium, 2013a,b; Irish Schizophrenia Genomics and the Wellcome Trust Case Control, 2012; Mukherjee et al., 2014; Ripke et al., 2013; Schizophrenia Psychiatric Genome-Wide 
Association Study Consortium, 2011; Schizophrenia Working Group of the Psychiatric Genomics, 2014). This latter interval has yielded associations which were significant in the context of multiple testing across the entire genome, in different studied populations, and when analysing either SNPs (single nucleotide polymorphisms) or Runs of Homozygozity ( $\mathrm{ROH})$. An association of $\mathrm{ROH}$ with a trait indicates a recessive mode of action. In the study of Mukherjee et al. (2014), a ROH of 53 kb was significantly associated with schizophrenia, while a nearby extended haplotype of $58 \mathrm{~kb}$ was also associated with schizophrenia in an additive model (see Fig. 1). Allotypes of HLA proteins, which are defined by their immunohistochemical properties, have also been associated with schizophrenia, including HLA-C ${ }^{*} 01: 02$ (Irish Schizophrenia Genomics and the Wellcome Trust Case Control, 2012), HLAB*08:01 and HLA-DRB1*01:03 (Stefansson et al., 2009).

HLA proteins are main actors of immunity. In immune cells, the high variability of these transmembrane proteins contributes to the recognition of "self" cells, mediating both innate and adaptive immunity (Traherne, 2008; Trowsdale and Knight, 2013). HLA class I proteins present peptides to cytotoxic T-cells (CD8+), while HLA class II proteins present peptides to helper T-cells (CD4+) participating in the production of antibodies by B-cells (Shiina et al., 2009; Trowsdale and Knight, 2013). The expression of cytokines and genes of the HLA region, critical components of the immune response, may be altered in peripheral immune cells and in glial cells of schizophrenic patients (Bernstein et al., 2015; Goudriaan et al., 2014; Miller et al., 2011; Sinkus et al., 2013). Several studies have shown a co-segregation of autoimmune diseases, chronic inflammation and maternal infection with schizophrenia (Bergink et al., 2014; Bernstein et al., 2015; Horvath and Mirnics, 2014; Knuesel et al., 2014; Stringer et al., 2014). This has led to the hypothesis that immunological disturbances are a key factor in the etiology of schizophrenia, notably through the role of microglial cells and astrocytes in the immune response in the brain (Bernstein et al., 2015; Horvath and Mirnics, 2014). While HLA proteins have been mainly studied for their roles in immunity, recent studies in rodents also point to functions in the neurons, notably of the MHC class I (MHCI) proteins (Boulanger, 2009; Elmer and McAllister, 2012; Lee et al., 2014; Shatz, 2009). Their attributes appear to have been co-opted in the brain to influence neuronal connectivity and synaptic plasticity (Elmer and McAllister, 2012). MHCI proteins are expressed in a brain tissue-specific and developmental stage-specific manner (Liu et al., 2013; Zhang et al., 2013a), and may be major actors in developmental synaptic pruning, which is dependent on neuronal activity (Glynn et al., 2011; Lee et al., 2014). MHCI proteins are particularly expressed in neurons of the lateral geniculate nucleus of the thalamus (Zhang et al., 2013b), and also affect axonal and neurite outgrowth of hippocampal neurons in vitro (Bilousova et al., 2012). In addition, knock-out mice for the homologous immune system show increased ocular dominance, as well as aberrant patterns of Long-Term Potentiation (LTP) and Long-Term Depression (LTD) in the hippocampus (Datwani et al., 2009; Elmer and McAllister, 2012; Huh et al., 2000). As these observations indicate effects of the MHC on thalamus and hippocampus development and function, the possibility also arises that the MHC is involved in dysfunction linked to these structures (Lee et al., 2014; McAllister, 2014).

The thalamus and the hippocampus are two functionally interconnected and bilaterally paired structures (Stein et al., 2000). The thalamus has been extensively studied in relation to relaying and processing sensory and motor information, as well as regulating consciousness and sleep (Sherman and Guillery, 2000). Volumetric reductions of the thalamus, and alterations of its leftright volumetric asymmetry, have been reported to associate with schizophrenia (Adriano et al., 2010; Byne et al., 2009; Csernansky et al., 2004; Gaser et al., 2004; Haukvik et al., 2013; Horga et al.,
2011; Jaaro-Peled et al., 2010; Portas et al., 1998; Qiu et al., 2009; Smith et al., 2011). The hippocampus has well-studied roles in long-term and working memory, which are abilities that are often impaired in people with schizophrenia (Aleman et al., 1999; Libby et al., 2013). A reduction of hippocampal volume and/or alterations of hippocampal asymmetry have been found by independent studies and meta-analyses to associate with schizophrenia (Adriano et al., 2012; Gruber et al., 2008; Hasan et al., 2011; Haukvik et al., 2013; Jaaro-Peled et al., 2010; Shenton et al., 2010; Shepherd et al., 2012).

On the basis of the above three lines of evidence, i.e. association of common HLA genetic variants with schizophrenia, neuronal MHC gene functions particularly in the thalamus and hippocampus, and alterations of thalamus and hippocampus volumes and asymmetries in schizophrenia, we hypothesized that common variations of the HLA would affect volumetric and asymmetric variation of the thalamus and/or the hippocampus. We obtained measures of left and right thalamus and hippocampus volumes from MRI data derived from 1265 healthy individuals, from whom DNA had previously been collected and genotyped on genomewide SNP arrays. Specific evolutionary processes have shaped the HLA region, notably pathogenic pressure and human migrations (Parham and Moffett, 2013; Prugnolle et al., 2005; Traherne, 2008), and these processes have led to the HLA region presenting one of the lowest recombination rates of the human genome, as well as a high genetic diversity, reflected in a large number of extended haplotypes (Cullen et al., 2002). We therefore used a reference population genetic dataset that was specifically targeted to the HLA region, in order to accurately impute genotypes at high density across the region in our 1265 participants (Franke et al., 2010; Guadalupe et al., 2014a,b). Imputation was performed for common genetic variation as well as for HLA amino-acids (AA) and classically defined HLA allotypes (de Bakker and Raychaudhuri, 2012; Jia et al., 2013). We tested all of these polymorphisms for associations with thalamus and hippocampal volumes separately, using bivariate models to incorporate left and right volumes, in order to allow for potentially asymmetric effects without multiple testing of the two sides independently.

\section{Material and methods}

\subsection{Participants}

MRI and genetic data were obtained from 1303 self-reported healthy, unrelated volunteers (including many university students) at the Donders Center for Cognitive Neuroscience, Nijmegen, the Netherlands. This dataset has been described previously and is known as the BIG (brain imaging genetics) dataset, collected as part of the Cognomics initiative (Franke et al., 2010; Guadalupe et al., 2014a,b). The age range spanned from 18 to 41 years, with a median age of 22 years. There were 748 females and 555 males. All individuals participating in this study gave written informed consent to the analysis of their DNA in relation to their brain MRI scans.

\subsection{Brain MRI data}

MRI data were acquired with a 1.5 Tesla Siemens Sonata or Avanto scanner, or else a 3 Tesla Siemens Trio or TimTrio scanner (Siemens Medical Systems, Erlangen, Germany) (Guadalupe et al., 2014b). As described previously in detail (Guadalupe et al., 2014b), corrections were applied against field non-homogeneities, implemented in both the Siemens scanners and also in the FreeSurfer software (Fischl et al., 2002). Subcortical volumetric measures were estimated after segmentation by FreeSurfer 
(Fischl et al., 2002) using the standard "-recon-all” processing pipeline and default parameters. Left and right thalamic and hippocampal volumes for each participant were extracted for this study, as well as their supra-tentorial volume (i.e. cerebrum volume). Any individuals showing a volumetric measure more extreme than three times the standard deviation from the group mean were excluded from subsequent analyses (SPSS software (IBM)). After this exclusion, there remained 1265 individuals. We removed the covariate effects of age, sex, scanner field strength and supra-tentorial volumes from the volumetric measures by linear regression and retention of the residuals. The resulting residualized measures of left and right thalamus volume were correlated (Pearson's correlation $r=0.68$ ), as were the volumes of left and right hippocampus $(r=0.76)$. The hippocampus and thalamus measures were also inter-correlated, but to a lower extent ( $r$ ranging from 0.220 to 0.310 ). See the supplementary information for a full correlation table.

\subsection{Genetic and allotypic data}

The reference population dataset for genotype imputation was derived from the T1DGC cohort and was described by (Jia et al., 2013). This is a reference dataset targeted specifically at the HLA region, and comprises 5225 unrelated British individuals of European descent, genotyped for 7258 SNPs spanning the HLA, and also assigned with the presence/absence of 424 classical allotypes for HLA-A, HLA-B, HLA-C, HLA-DRB1, HLA-DQA1, HLA-DPA1 and HLA-DPB1, as well as 1276 individual amino acids at variable sites in the HLA proteins. HLA allotypes are defined by threedimensional protein structure that is recognised by specific antibodies, and must be imputed with reference to multiple SNP genotypes (Jia et al., 2013). The allotypes are defined at two-digit resolution to define groups (e.g. HLA-A*01), and also at four-digit resolution to define HLA immunoglobulin forms more specifically (e.g. HLA-A*01:01) (Marsh et al., 2010).

The generation of Affymetrix 6.0 array-based genotypes in the BIG dataset, together with the quality control procedures employed, has been described previously (Guadalupe et al., 2014b). The genotypes were adjusted to the forward strand using the information given by Affymetrix to avoid ambiguity in subsequent steps. Genotypes from 1868 SNPs spanning the HLA locus in the BIG dataset were extracted to span the HLA region as defined by (Jia et al., 2013), i.e. Hg\#19:chr6:29494897-33160425. Only SNPs with minor allele frequencies greater than 0.05 in the BIG dataset were used for imputation. This was to allow for the possibility of slight genetic stratification between the reference dataset (British participants) and the BIG dataset (mostly Dutch participants), which would affect rare genetic variation most markedly. Imputation of SNP genotypes, allotypes and HLA amino acids was performed with the program SNP2HLA (Jia et al., 2013) and the program BEAGLE (Browning and Browning, 2009), using the protocol described by (Jia et al., 2013). After imputation SNPs were removed when the imputation $r^{2}$ values were lower than 0.3 and/or when they deviated significantly from HardyWeinberg equilibrium at a threshold of $P<0.01$ (Purcell et al., 2007). This produced imputed genotype data for 7256 SNPs, as well as calls for 1276 HLA amino acids, 126 HLA allotypes at a two-digit resolution, and 298 HLA allotypes at a four-digit resolution. Imputed HLA allotypes and HLA amino acids were then coded as binary traits to facilitate further analyses, i.e. as presence/absence of a given form (Jia et al., 2013). Individuals with imputed SNP genotype call rates below 0.9 were discarded. Haplotypic reconstruction, performed by the program SNP2HLA, was used with respect to the alleles of the five SNPs that showed significant association with a reduction of thalamus volume (see Section 3), to manually check against extended combinations of predicted HLA allotypes, i.e. to investigate whether the trait-associated SNP haplotypes related to extended HLA haplotypes (de Bakker et al., 2006; Jia et al., 2013; Yunis et al., 2003). Linkage disequilibrium structure of the HLA locus in the BIG dataset, based only on the SNP data, was assessed by Haploview (Barrett et al., 2005).

\subsection{Bivariate association tests for volumetric measures}

Quantitative trait locus (QTL) association tests were performed separately for each polymorphism and each structure, i.e. the hippocampus and thalamus, using the Plink.multivariate software (Ferreira and Purcell, 2009). For each structure, the left and right volumes were input simultaneously into a single bivariate association model. One association test per SNP and per structure was therefore performed, each time with simultaneous respect to two continuous variables (left and right volumes). Bivariate analysis is a robust analysis for correlated measures which can deliver increased statistical power when a genetic locus effects co-variance in two measures, compared to testing the measures separately and performing weighted adjustment for multiple testing (Ferreira and Purcell, 2009). The software computed the linear combination of the left and right volumes that correlated most strongly across participants with the polymorphism being tested, in an additive genetic model (Ferreira and Purcell, 2009). The relationships between the SNP and each measure separately are given by the correlation of the linear combination with each measure. Pointwise empirical $P$ values were derived by label-swapping permutation (randomising genotype to trait correspondence) implemented within Plink.multivariate (using the $\max (\mathrm{T})$ option with 1.000.000 permutations) (Ferreira and Purcell, 2009; Purcell et al., 2007). We used Bonferroni correction for multiple testing, in which we considered an independent number of tests (1957) corresponding to the number of LD blocks in our cohort (defined by Haploview with an LD $r^{2}$ threshold $>0.8,383$ LD blocks), plus the number of imputed allotypes at a four-digit resolution (298) and the inferred amino acids (1276), as previously described (Jia et al., 2013). This gave a threshold nominal $P<=0.000026$ for one structure, to correspond to a corrected alpha level of 0.05 for that structure. As the thalamus and the hippocampus were analysed separately, we also multiplied the $P$ values by a factor of two.

For the most significantly associated SNP in the bivariate association analysis (rs17194174 with the thalamus, see below), we also performed univariate linear regressions of the left and right volumes on rs17194174 genotypes (in an additive model) and then tested for heterogeneity of the effect sizes (Clogg, 1995), to test for a lateralized effect.

\section{Results}

\subsection{Bivariate association analysis across the HLA region}

After multiple testing correction, five SNPs (rs12663724, rs7753935, rs11967911, rs17187805 and rs17194174 showed significant bivariate associations with left and right thalamus volumes (corrected $P<0.05$; Fig. 1 ; see supplementary data 1 for how these associations loaded onto the left and right volumes separately). The five SNPs are in strong $\operatorname{LD}\left(r^{2}>0.97 D^{\prime}>0.99\right.$, Fig. 1$)$ within a $2.3 \mathrm{~kb}$ intergenic region of the HLA class I locus (hg19:chr6:30059592-30061910), between the genes RNF39 and TRIM31. The most significant bivariate association was obtained for rs17194174 (uncorrected $P=0.000001$; corrected $P=0.0039$; minor allele frequency $=0.14$ ). The minor allele was associated with a reduction of thalamus volume. As a check on the consistency of this association we also tested it separately in data derived from the $1.5 \mathrm{~T}$ and $3 \mathrm{~T}$ scans (1.5T scanner, 629 participants, 


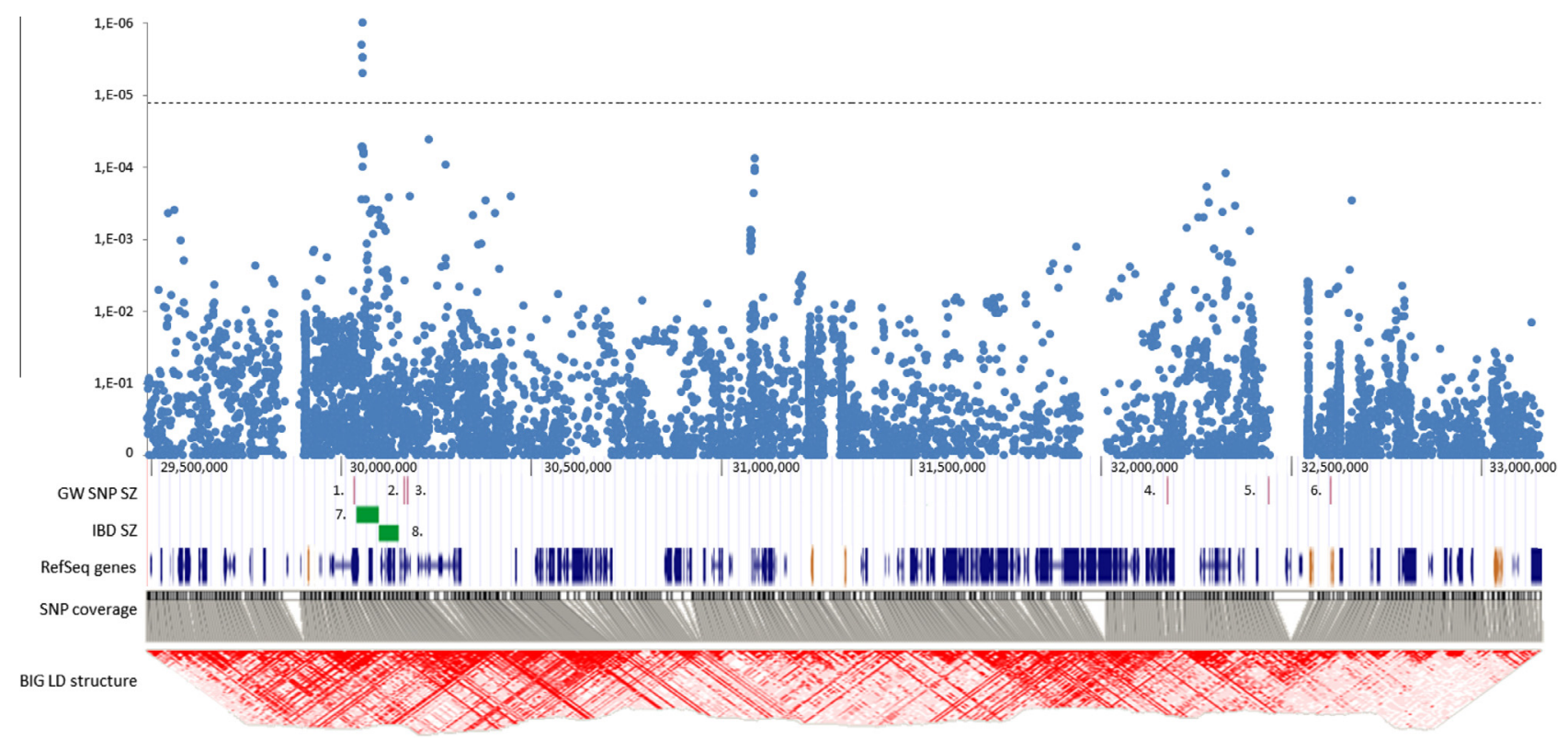

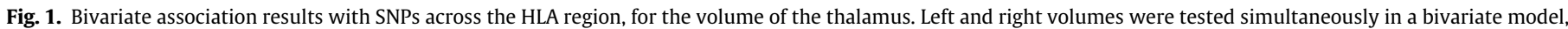

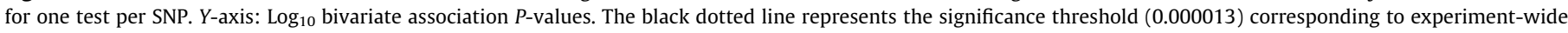

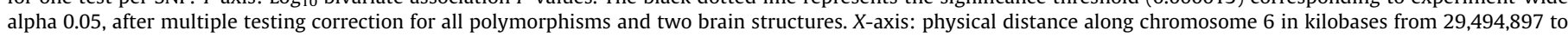

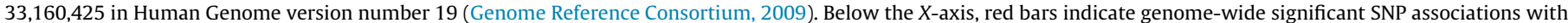

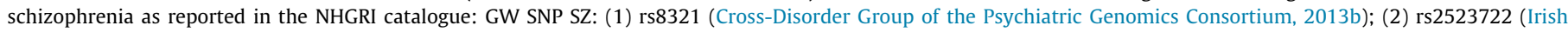

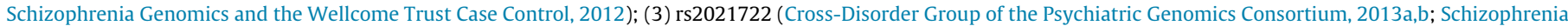

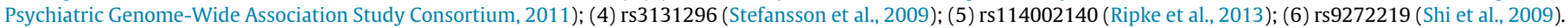

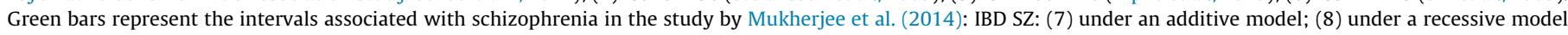

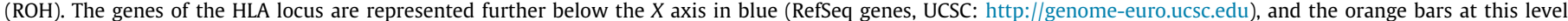

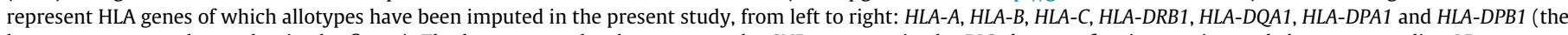

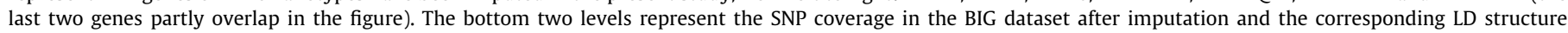
calculated by Haploview (Barrett et al., 2005).

$P=0.0039 ; 3 T$ scanner, 636 participants, $P=0.000095)$. In the bivariate association model of the data combined, the left thalamus loading was -0.951 , and right hemisphere loading was -0.416 , meaning that the linear combination of these traits that was most strongly associated with the SNP correlated more strongly with the left than the right thalamus volume (supplementary data 1). In other words, the effect appeared somewhat stronger on the left thalamus. Univariate analyses of rs17194174 in relation to left and right thalamus volumes separately yielded beta $=166.05$ (S.E. $=34.53), \quad P=0.0000017$ for the left and beta $=67.59$ (S.E. $=31.01), P=0.0295$ for the right. Testing for heterogeneity of these effects (Clogg, 1995) yielded $z=2.12, P=0.034$, indicating a significantly left-lateralized effect. Univariate regression of the volumetric asymmetry index for the thalamus, calculated as ((Left - Right)/(Left + Right)), upon the genotypes of rs17194174 in an additive linear model, resulted in a significant association with beta $=-0.091, P=0.00077$. This association is within the previously identified interval in which an extended SNP haplotype was reported to be associated with schizophrenia under an additive model by (Mukherjee et al., 2014) (see Fig. 1). It is also within the same LD block as rs8321 (LD block:hg\#19:chr6:2989967730066031; $r^{2}>0.8 D^{\prime}>1$; Fig. 1 ), a SNP that was previously associated with schizophrenia at a genome-wide significant level (Cross-Disorder Group of the Psychiatric Genomics Consortium, 2013b). An inspection of our imputed SNP haplotypes, in relation to extended HLA haplotypes (i.e. combinations of HLA allotypes), revealed that the five SNPs significantly associated with thalamus volume did not clearly predict any specific subset of extended HLA haplotypes. There were 371 imputed SNP haplotypes which carried the 'thalamus volume reduction' alleles at these five SNPs, out of 2530 imputed SNP haplotypes in total (data not shown). The diversity of combinations of HLA allotypes estimated from these haplotypes indicates that these five SNPs do not tag any specific extended HLA haplotype.

After correction for multiple testing (corrected $P>0.05$ ), we found no significant association of SNPs with hippocampus volume (supplementary data 1). The SNP rs17194174 was not associated with hippocampus volume $(P=0.098)$. Also there was no significant association with either of the two brain regions for HLA allotypes or HLA amino acids (supplementary data 1).

\subsection{SNPs previously associated with schizophrenia}

Six HLA-region SNPs have been reported in the National Human Genome Research Institute catalogue (NHGRI catalogue: www. genome.gov/gwastudies; (Hindorff et al., 2014)) to show significant associations with schizophrenia after correction for multiple testing in GWAS studies (see Fig. 1). Five of these SNPs were successfully imputed in the present study. As a targeted secondary investigation following our initial screening across the HLA region, we report in Table 1 the nominal (not corrected) association $P$ values for these five SNPs with thalamus and hippocampus volumes in the BIG dataset, as derived from bivariate association analysis (i.e. one statistical test per SNP per structure, inputting left and right volumes simultaneously). Among these SNPs, rs8321 (Cross-Disorder Group of the Psychiatric Genomics Consortium, 2013b) was nominally associated with hippocampus and thalamus volumes $(P<0.05$; Table 1$)$, with the minor allele being associated with reduced thalamic volume and increased hippocampal volume. No information on the risk/protective status of this allele was reported in the GWAS study by the Cross-Disorder Group of the Psychiatric Genomics Consortium (Cross-Disorder Group of 
Table 1

A schizophrenia-associated HLA locus affects thalamus volume and asymmetry.

\begin{tabular}{|c|c|c|c|c|c|c|c|}
\hline Polymorphism & Position ${ }^{*}$ & MAF & $\begin{array}{l}\text { Thalamus } \\
P \text {-value }\end{array}$ & $\begin{array}{l}\text { Hippocampus } \\
P \text {-value }\end{array}$ & $\begin{array}{l}\text { SCZ } \\
P \text {-value }\end{array}$ & $\begin{array}{l}\text { Nearest } \\
\text { gene }\end{array}$ & References \\
\hline rs2523722 & 30273252 & 0.19 & 0.86 & 0.14 & $1.00 \mathrm{E}-16$ & TRIM26 & Irish Schizophrenia Genomics and the Wellcome Trust Case Control (2012) \\
\hline rs2021722 & 30282110 & 0.20 & 0.73 & 0.17 & $2.00 \mathrm{E}-12$ & TRIM26 & $\begin{array}{l}\text { Cross-Disorder Group of the Psychiatric Genomics Consortium (2013a,b), } \\
\text { Schizophrenia Psychiatric Genome-Wide Association Study Consortium } \\
\text { (2011) }\end{array}$ \\
\hline rs3131296 & 32280971 & 0.14 & 0.0075 & 0.29 & $2.00 \mathrm{E}-10$ & NOTCH4 & Stefansson et al. (2009) \\
\hline rs8321 & 30140501 & 0.11 & 0.017 & 0.012 & $8.00 \mathrm{E}-09$ & ZNRD1 & Cross-Disorder Group of the Psychiatric Genomics Consortium (2013b) \\
\hline rs9272219 & 32710247 & 0.29 & 0.14 & 0.39 & $7.00 \mathrm{E}-08$ & $\begin{array}{l}\text { HLA- } \\
\text { DQA1 }\end{array}$ & Shi et al. (2009) \\
\hline
\end{tabular}

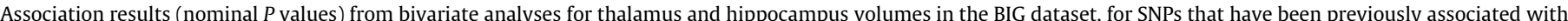
schizophrenia at a genome-wide significant level and recorded in the NHGRI catalogue. MAF: minor allele frequency.

* Genomic position on chromosome 6, in Human Genome version number 19 (Genome Reference Consortium, 2009).

\# $P$-values for association with schizophrenia reported in the corresponding publications.

the Psychiatric Genomics Consortium, 2013b). Also, rs3131296 (Stefansson et al., 2009) was nominally associated with thalamus volume $(P=0.0075)$, with the minor allele being associated with reduced volume. This was the protective allele for schizophrenia in the GWAS study by Stefansson et al. (2009).

In addition to the HLA schizophrenia-associated SNPs reported in the NHGRI catalogue, there are two further significant HLA SNPs that have been reported in recent GWAS papers, rs114002140 and rs115329265 (Ripke et al., 2013; Schizophrenia Working Group of the Psychiatric Genomics, 2014). However, these were selected to represent the entire extended HLA locus ( $\sim 8 \mathrm{Mb})$, in order to account for high LD across the locus, which actually resulted in many SNPs being associated with schizophrenia at a GWAS-significant level in their analyses, but for which individual association results were not reported. The SNP rs114002140 was not successfully imputed in our study, and rs115329265 was outside the interval defined in our imputation reference dataset.

\section{Discussion}

In this study we imputed genotypes for 1265 healthy participants of European descent, for SNPs at a high density across the HLA region, as well as for HLA allotypes and HLA amino acids, by use of genome-wide genotype data together with a reference dataset that was targeted specifically at the HLA region. We found a significant association between a locus in the HLA region and the volume of the human thalamus. The effect was significantly lateralized towards the left thalamus, although the volume of the right thalamus was also affected to a lesser degree. This pattern resulted in the association influencing volumetric asymmetry of the thalamus. The significantly associated SNPs are located within a $2.3 \mathrm{~kb}$ intergenic locus of the HLA region, and the minor alleles were associated with a reduction of thalamus volume, which may be indicative of negative selection.

Our study was motivated by three observations: HLA genes have been shown to have neuronal affects within the thalamus and hippocampus; altered thalamus and hippocampus volumes and/or lateralization have been associated with schizophrenia; common SNPs within the HLA region have been associated with schizophrenia. It is therefore striking that the lateralized genetic effect we detected on left thalamus volume is located within an interval in which an extended SNP haplotype was reported to be associated with schizophrenia in a recent genome-wide screening study (Mukherjee et al., 2014). Another nearby interval (Fig. 1) was significantly associated with schizophrenia in an analysis of runs of homozygosity, i.e. under a recessive genetic model (Mukherjee et al., 2014). Furthermore, the two intervals reported by Mukherjee et al. (2014) are closely flanked by three SNPs that have been reported to associate with schizophrenia at a significant level in GWAS studies (rs8321, (Cross-Disorder Group of the Psychiatric Genomics Consortium, 2013b); rs2523722, (Irish Schizophrenia Genomics and the Wellcome Trust Case Control, 2012); rs2021722 (Cross-Disorder Group of the Psychiatric Genomics Consortium, 2013a,b; Schizophrenia Psychiatric Genome-Wide Association Study Consortium, 2011)). One of these SNPs (rs8321) showed nominally significant association with thalamus and hippocampus volumes in our dataset. In our set of healthy participants we are not able to test more directly for pleiotropic effects of these polymorphisms on brain structural volumes and schizophrenia. However, the convergent findings indicate that a relatively small interval, of $2.3 \mathrm{~kb}$ within the overall HLA (Fig. 1), harbours a variant or variants that influence anatomy of the thalamus, and that the molecular mechanisms involved may relate to HLA-locus effects on susceptibility to schizophrenia.

The mechanisms are not known by which genetic variants in the HLA influence schizophrenia (Bernstein et al., 2015; Byne et al., 2009; McAllister, 2014), and likewise the SNPs associated with thalamus volume and asymmetry that we report here will need further functional investigation to understand the mechanisms involved. The lack of any discernible extended HLA haplotype linked to the five SNPs and the absence of association of HLA allotypes with our volumetric measures suggest that these SNPs have no straightforward reflection at the level of allotypes of HLA proteins. The intergenic interval that contains the five SNPs also contains several indications for regulatory elements of gene transcription (UCSC: http://genome-euro.ucsc.edu). Chip-seq data indicate binding of Polymerase II (Encode Project Consortium, 2012), the major actor of transcription, as well as the modified forms of histone proteins H3K4Me1 and H3K27ac (Encode Project Consortium, 2012), and the transcriptional factor TCF7L2 which often localize at enhancer loci (Encode Project Consortium, 2012). Binding of the proteins BAF150 and BAF170, involved in chromatin remodelling, is also indicated by Chip-seq data (Encode Project Consortium, 2012). Due to the unusual genetic structure of the HLA locus, cis-regulatory elements are often particularly strong for genes of the same LD block (McRae et al., 2014; Traherne, 2008). Recent expression-quantitative trait locus (eQTL) analyses, based on tissue from post mortem brain samples, has shown that the minor alleles of the five SNPs associated with thalamus volume and asymmetry affect the level of expression of ZNRD1-AS, which is a non-coding antisense RNA to the gene ZNRD1 (Braineac: http://www.braineac.org/) (Ramasamy et al., 2014). eQTL analyses in monocytes and lymphoblastoid cell lines have also indicated a high density of putative cis-regulatory elements within our associated interval, mainly affecting the expression of two genes within the same LD block: HLA-A and ZNRD1 (http://eqtl.uchicago.edu) (Montgomery et al., 2010; Veyrieras 
et al., 2008; Zeller et al., 2010). HLA-A is a HLA class I protein (see Section 1). ZNRD1 is not well characterized, and encodes an RNA polymerase enzyme that affects cell proliferation in stomach cancer (Hong et al., 2005). While ZNRD1-AS has no known biological role, several lines of evidence suggest that one or both of HLA-A and ZNRD1 have neuronal functions (Boulanger, 2009; Elmer and McAllister, 2012; Xie et al., 2013) and possible roles in schizophrenia (Bergen et al., 2012; Cross-Disorder Group of the Psychiatric Genomics Consortium, 2013b; McAllister, 2014) (in addition to the evidence for neuronal function of HLA class I proteins outlined in the Introduction). Both of these genes are expressed in the thalamus (Allen Brain Atlas: http://human.brain-map.org; Braineac: http://www.braineac.org/ (Ramasamy et al., 2014)), and Chip-seq data in mouse brain has suggested that their homologues (H2-K1 and Znrd1) are regulated by the transcriptional factor Pax6 (Xie et al., 2013), a major actor in the developing central nervous system. Notably Pax6 interacts with Baf150 and Baf177 to regulate cerebral size and thickness (Tuoc et al., 2013; Xie et al., 2013). Furthermore, both HLA-A and ZNRD1 contain SNPs associated with schizophrenia by GWAS; rs2524005 is intronic in HLA-A (Bergen et al., 2012) and rs8321 is in the $3^{\prime}$ untranslated region of ZNRD1 (Cross-Disorder Group of the Psychiatric Genomics Consortium, 2013b). In addition, HLA-A expression has shown evidence for alteration in schizophrenic patients (Sinkus et al., 2013). The most significantly associated SNP outside the HLA locus, in another recent GWAS study, is linked to a locus affecting HLA-A mRNA level in brain (Schizophrenia Working Group of the Psychiatric Genomics, 2014).

Although our study was partly motivated by neuronal expression of HLA genes in the thalamus and the hippocampus (Boulanger, 2009; Elmer and McAllister, 2012; Lee et al., 2014; Shatz, 2009), our findings may also relate to glial cells whose contributions in schizophrenia have recently been extensively shown (Bergink et al., 2014; Bernstein et al., 2015; Duncan et al., 2014; Goudriaan et al., 2014; Roussos and Haroutunian, 2014). Among glial cells, the astrocytes and the microglial cells are of particular interest because of their expression of several immune proteins, such as HLA Class II proteins (Bernstein et al., 2015). Astrocytes are main actors of diverse brain functions such as the control of neuronal metabolism and homeostasis, the regulation of neurotransmitter release and the modulation of the immune response. Microglial cells act as the naturally resident mononuclear phagocyte system cells of the brain, processing the phagocytosis of infectious agents and neurons undergoing apoptosis, as well as acting in relation to axon remodelling and synaptic pruning (Bernstein et al., 2015). This immunological perspective is consistent with altered immune responses and neuroinflammation that has sometimes been observed in schizophrenic patients, suggesting autoimmunity and inflammation as potential vulnerability factors for the development of schizophrenia (Bergink et al., 2014; Bernstein et al., 2015; Horvath and Mirnics, 2014; Knuesel et al., 2014; Sainz et al., 2013; Stringer et al., 2014). The neuronal and glial hypotheses are non-exclusive. Both classes of cells should be considered in future functional studies of the HLA locus associated with thalamus volume.

Targeted functional experiments will be necessary to test for the regulation of HLA-A, ZNRD1 and/or ZNRD1-AS by our locus of interest in neurons and also in glial cells and immune cells. It is possible that this locus, by acting as a regulator of the expression of HLA-A, ZNRD1 and/or ZNRD1-AS, affects growth of the thalamus in a lateralized manner and increases the risk for schizophrenia. Our data add to a growing literature implicating this specific region of the HLA locus in neurodevelopment and psychiatric disease, and identify a possible brain structural correlate in this regard.

The use of a high density imputation reference panel that is specifically targeted to the HLA region, based on a large dataset, was a strength of our study. We recommend this approach in future association mapping studies of the HLA region, because it offers greater spatial genomic resolution in this complex, high LD region of the genome than standard GWAS imputation approaches. The results from our study will be enhanced by follow-up in additional datasets, using this same imputation procedure.

\section{Disclosure}

The authors declare no conflicts of interest.

\section{Acknowledgments}

This work makes use of the BIG (Brain Imaging Genetics) database, first established in Nijmegen in 2007. This resource is now part of Cognomics, a joint initiative by researchers of the Donders Centre for Cognitive Neuroimaging, the Human Genetics and Cognitive Neuroscience departments of the Radboud University Medical Centre and the Max Planck Institute for Psycholinguistics. The Cognomics Initiative is supported by the participating departments and centers. The authors wish to thank all persons who kindly participated in this research. During the writing of the manuscript, Nicolas Brucato was funded by the ERC project MesAndLin(g)k (ERC 295918).

\section{Appendix A. Supplementary data}

Supplementary data associated with this article can be found, in the online version, at http://dx.doi.org/10.1016/j.bbi.2015.02.021.

\section{References}

Adriano, F., Caltagirone, C., Spalletta, G., 2012. Hippocampal volume reduction in first-episode and chronic schizophrenia: a review and meta-analysis. Neuroscientist 18, 180-200.

Adriano, F., Spoletini, I., Caltagirone, C., Spalletta, G., 2010. Updated meta-analyses reveal thalamus volume reduction in patients with first-episode and chronic schizophrenia. Schizophr. Res. 123, 1-14.

Aleman, A., Hijman, R., de Haan, E.H., Kahn, R.S., 1999. Memory impairment in schizophrenia: a meta-analysis. Am. J. Psychiatry 156, 1358-1366.

American Psychiatric Association, 2013. Diagnostic and statistical manual of mental disorders (5th ed.), Washington, DC.

Andreassen, O.A., Harbo, H.F., Wang, Y., Thompson, W.K., Schork, A.J., Mattingsdal, M., Zuber, V., Bettella, F., Ripke, S., Kelsoe, J.R., Kendler, K.S., O’Donovan, M.C., Sklar, P., The Psychiatric Genomics Consortium Bipolar, D., Schizophrenia Work G., The International Multiple Sclerosis Genetics, C., McEvoy, L.K., Desikan, R.S., Lie, B.A., Djurovic, S., Dale, A.M., The Psychiatric Genomics Consortium, P.G.C.B.D., Schizophrenia Work, G., The International Multiple Sclerosis Genetics Consortium, I., 2014. Genetic pleiotropy between multiple sclerosis and schizophrenia but not bipolar disorder: differential involvement of immune-related gene loci. Mol. Psychiatry.

Barrett, J.C., Fry, B., Maller, J., Daly, M.J., 2005. Haploview: analysis and visualization of LD and haplotype maps. Bioinformatics 21, 263-265.

Bergen, S.E., O’Dushlaine, C.T., Ripke, S., Lee, P.H., Ruderfer, D.M., Akterin, S., Moran, J.L., Chambert, K.D., Handsaker, R.E., Backlund, L., Osby, U., McCarroll, S., Landen, M., Scolnick, E.M., Magnusson, P.K., Lichtenstein, P., Hultman, C.M., Purcell, S.M. Sklar, P., Sullivan, P.F., 2012. Genome-wide association study in a Swedish population yields support for greater CNV and MHC involvement in schizophrenia compared with bipolar disorder. Mol. Psychiatry 17, 880-886.

Bergink, V., Gibney, S.M., Drexhage, H.A., 2014. Autoimmunity, inflammation, and psychosis: a search for peripheral markers. Biol. Psychiatry 75, 324-331.

Bernstein, H., Steiner, J., Guest, P.C., Dobrowolny, H., Bogerts, B., 2015. Glial cells as key players in schizophrenia pathology: recent insights and concepts of therapy. Schizophr. Res. 161, 4-18.

Bilousova, T., Dang, H., Xu, W., Gustafson, S., Jin, Y., Wickramasinghe, L., Won, T. Bobarnac, G., Middleton, B., Tian, J., Kaufman, D.L., 2012. Major histocompatibility complex class I molecules modulate embryonic neuritogenesis and neuronal polarization. J. Neuroimmunol. 247, 1-8.

Boulanger, L.M., 2009. Immune proteins in brain development and synaptic plasticity. Neuron 64, 93-109.

Browning, B.L., Browning, S.R., 2009. A unified approach to genotype imputation and haplotype-phase inference for large data sets of trios and unrelated individuals. Am. J. Hum. Genet. 84, 210-223.

Byne, W., Hazlett, E.A., Buchsbaum, M.S., Kemether, E., 2009. The thalamus and schizophrenia: current status of research. Acta Neuropathol. 117, 347-368. 
Clogg, C.C., 1995. Chapter 6 latent class models, Handbook of Statistical Modeling for the Social and Behavioral Sciences. Plenum Press, New York.

Cross-Disorder Group of the Psychiatric Genomics Consortium, 2013a. Genetic relationship between five psychiatric disorders estimated from genome-wide SNPs. Nat. Genet. 45, 984-994.

Cross-Disorder Group of the Psychiatric Genomics Consortium, 2013b. Identification of risk loci with shared effects on five major psychiatric disorders: a genome-wide analysis. Lancet 381, 1371-1379.

Csernansky, J.G., Schindler, M.K., Splinter, N.R., Wang, L., Gado, M., Selemon, L.D., Rastogi-Cruz, D., Posener, J.A., Thompson, P.A., Miller, M.I., 2004. Abnormalities of thalamic volume and shape in schizophrenia. Am. J. Psychiatry 161, 896902.

Cullen, M., Perfetto, S.P., Klitz, W., Nelson, G., Carrington, M., 2002. High-resolution patterns of meiotic recombination across the human major histocompatibility complex. Am. J. Hum. Genet. 71, 759-776.

Datwani, A., McConnell, M.J., Kanold, P.O., Micheva, K.D., Busse, B., Shamloo, M., Smith, S.J., Shatz, C.J., 2009. Classical MHCI molecules regulate retinogeniculate refinement and limit ocular dominance plasticity. Neuron 64, 463-470.

de Bakker, P.I., McVean, G., Sabeti, P.C., Miretti, M.M., Green, T., Marchini, J., Ke, X. Monsuur, A.J., Whittaker, P., Delgado, M., Morrison, J., Richardson, A., Walsh, E.C., Gao, X., Galver, L., Hart, J., Hafler, D.A., Pericak-Vance, M., Todd, J.A., Daly, M.J., Trowsdale, J., Wijmenga, C., Vyse, T.J., Beck, S., Murray, S.S., Carrington, M. Gregory, S., Deloukas, P., Rioux, J.D., 2006. A high-resolution HLA and SNP haplotype map for disease association studies in the extended human MHC. Nat. Genet. 38, 1166-1172.

de Bakker, P.I., Raychaudhuri, S., 2012. Interrogating the major histocompatibility complex with high-throughput genomics. Hum. Mol. Genet. 21, R29-R36.

Duncan, L.E., Holmans, P.A., Lee, P.H., O’Dushlaine, C.T., Kirby, A.W., Smoller, J.W. Ongur, D., Cohen, B.M., 2014. Pathway analyses implicate glial cells in schizophrenia. PLoS One 9, e89441.

Elmer, B.M., McAllister, A.K., 2012. Major histocompatibility complex class proteins in brain development and plasticity. Trends Neurosci. 35, 660-670.

Encode Project Consortium, 2012. An integrated encyclopedia of DNA elements in the human genome. Nature 489, 57-74.

Ferreira, M.A., Purcell, S.M., 2009. A multivariate test of association. Bioinformatics $25,132-133$.

Fischl, B., Salat, D.H., Busa, E., Albert, M., Dieterich, M., Haselgrove, C., van der Kouwe, A., Killiany, R., Kennedy, D., Klaveness, S., Montillo, A., Makris, N., Rosen, B., Dale, A.M., 2002. Whole brain segmentation: automated labeling of neuroanatomical structures in the human brain. Neuron 33, 341-355.

Franke, B., Vasquez, A.A., Veltman, J.A., Brunner, H.G., Rijpkema, M., Fernandez, G., 2010. Genetic variation in CACNA1C, a gene associated with bipolar disorder influences brainstem rather than gray matter volume in healthy individuals. Biol. Psychiatry 68, 586-588.

Gaser, C., Nenadic, I., Buchsbaum, B.R., Hazlett, E.A., Buchsbaum, M.S., 2004. Ventricular enlargement in schizophrenia related to volume reduction of the thalamus, striatum, and superior temporal cortex. Am. J. Psychiatry 161, 154156.

Genome Reference Consortium, 2009. Genome Reference Consortium Human Build 37 (GRCh37)

Glynn, M.W., Elmer, B.M., Garay, P.A., Liu, X.B., Needleman, L.A., El-Sabeawy, F. McAllister, A.K., 2011. MHCI negatively regulates synapse density during the establishment of cortical connections. Nat. Neurosci. 14, 442-451.

Goudriaan, A., de Leeuw, C., Ripke, S., Hultman, C.M., Sklar, P., Sullivan, P.F., Smit, A.B., Posthuma, D., Verheijen, M.H., 2014. Specific glial functions contribute to schizophrenia susceptibility. Schizophr. Bull. 40, 925-935.

Gruber, O., Falkai, P., Schneider-Axmann, T., Schwab, S.G., Wagner, M., Maier, W. 2008. Neuregulin-1 haplotype HAP(ICE) is associated with lower hippocampal volumes in schizophrenic patients and in non-affected family members. J. Psychiatr. Res. 43, 1-6.

Guadalupe, T. Willems, R.M.,Zwiers, M.P., Arias Vasquez, A., Hoogman, M., Hagoort, P., Fernández, G., Buitelaar, J., Franke, B., Fisher, S.E., Francks, C., 2014a. Differences in cerebral cortical anatomy of left- and right-handers. Front. Psychol. 5.

Guadalupe, T., Zwiers, M.P., Teumer, A. Wittfeld, K. Vasquez, A.A., Hoogman, M. Hagoort, P., Fernandez, G., Buitelaar, J., Hegenscheid, K., Volzke, H., Franke, B. Fisher, S.E., Grabe, H.J., Francks, C., 2014b. Measurement and genetics of human subcortical and hippocampal asymmetries in large datasets. Hum. Brain Mapp. 35, 3277-3289.

Hasan, A., Wobrock, T., Falkai, P., Schneider-Axmann, T., Guse, B., Backens, M., Ecker U.K., Heimes, J., Galea, J.M., Gruber, O., Scherk, H., 2011. Hippocampal integrity and neurocognition in first-episode schizophrenia: a multidimensional study. World J. Biol. Psychiatry.

Haukvik, U.K., Hartberg, C.B., Agartz, I., 2013. Schizophrenia - what does structural MRI show? Tidsskr Nor Laegeforen 133, 850-853.

Hindorff, L., MacArthur, J., Morales, J., Junkins, H., Hall, P., Klemm, A., Manolio, T., 2014. A Catalog of Published Genome-Wide Association Studies. Available at: <www.genome.gov/gwastudies>. Accessed (date of access)

Hong, L., Han, Y., Shi, R., Shao, X., Sun, L., Zhang, Y., Huang, D., Chen, Z., Zhang, G. Liang, J., Hu, S., Fan, D., 2005. ZNRD1 gene suppresses cell proliferation through cell cycle arrest in G1 phase. Cancer Biol. Ther. 4, 60-64.

Horga, G., Bernacer, J., Dusi, N., Entis, J., Chu, K., Hazlett, E.A., Haznedar, M.M., Kemether, E., Byne, W., Buchsbaum, M.S., 2011. Correlations between ventricular enlargement and gray and white matter volumes of cortex thalamus, striatum, and internal capsule in schizophrenia. Eur. Arch. Psychiatry Clin. Neurosci. 261, 467-476.
Horvath, S., Mirnics, K., 2014. Immune system disturbances in schizophrenia. Biol. Psychiatry 75, 316-323.

Huh, G.S., Boulanger, L.M., Du, H., Riquelme, P.A., Brotz, T.M., Shatz, C.J., 2000. Functional requirement for class I MHC in CNS development and plasticity. Science 290, 2155-2159.

Irish Schizophrenia Genomics Consortium, The Wellcome Trust Case Control Consortium, 2012. Genome-wide association study implicates HLA-C*01:02 as a risk factor at the major histocompatibility complex locus in schizophrenia. Biol. Psychiatry 72, 620-628.

Jaaro-Peled, H., Ayhan, Y., Pletnikov, M.V., Sawa, A., 2010. Review of pathological hallmarks of schizophrenia: comparison of genetic models with patients and nongenetic models. Schizophr. Bull. 36, 301-313.

Jia, X., Han, B., Onengut-Gumuscu, S., Chen, W.M., Concannon, P.J., Rich, S.S., Raychaudhuri, S., de Bakker, P.I., 2013. Imputing amino acid polymorphisms in human leukocyte antigens. PLoS One 8, e64683.

Knuesel, I., Chicha, L., Britschgi, M., Schobel, S.A., Bodmer, M., Hellings, J.A., Toovey, S., Prinssen, E.P., 2014. Maternal immune activation and abnormal brain development across CNS disorders. Nat. Rev. Neurol. 10, 643-660.

Lee, H., Brott, B.K., Kirkby, L.A., Adelson, J.D., Cheng, S., Feller, M.B., Datwani, A. Shatz, C.J., 2014. Synapse elimination and learning rules co-regulated by MHC class I H2-Db. Nature 509, 195-200.

Libby, L.A., Yonelinas, A.P., Ranganath, C., Ragland, J.D., 2013. Recollection and familiarity in schizophrenia: a quantitative review. Biol. Psychiatry 73, 944950

Liu, J., Shen, Y., Li, M., Shi, Q., Zhang, A., Miao, F., Liu, J., Wu, X., He, Y., Zhang, J., 2013. The expression pattern of classical MHC class I molecules in the development of mouse central nervous system. Neurochem. Res. 38, 290-299.

Marsh, S.G., Albert, E.D., Bodmer, W.F., Bontrop, R.E., Dupont, B., Erlich, H.A., Fernandez-Vina, M., Geraghty, D.E., Holdsworth, R., Hurley, C.K., Lau, M., Lee, K.W., Mach, B., Maiers, M., Mayr, W.R., Muller, C.R., Parham, P., Petersdorf, E.W., Sasazuki, T., Strominger, J.L., Svejgaard, A., Terasaki, P.I., Tiercy, J.M., Trowsdale, J., 2010. Nomenclature for factors of the HLA system, 2010. Tissue Antigens 75, 291-455.

McAllister, A.K., 2014. Major histocompatibility complex I in brain development and schizophrenia. Biol. Psychiatry 75, 262-268.

McRae, A.F., Powell, J.E., Henders, A.K., Bowdler, L., Hemani, G., Shah, S., Painter, J.N., Martin, N.G., Visscher, P.M., Montgomery, G.W., 2014. Contribution of genetic variation to transgenerational inheritance of DNA methylation. Genome Biol. 15, R73.

Miller, B.J., Buckley, P., Seabolt, W., Mellor, A., Kirkpatrick, B., 2011. Meta-analysis of cytokine alterations in schizophrenia: clinical status and antipsychotic effects. Biol. Psychiatry 70, 663-671.

Montgomery, S.B., Sammeth, M., Gutierrez-Arcelus, M., Lach, R.P., Ingle, C., Nisbett, J., Guigo, R., Dermitzakis, E.T., 2010. Transcriptome genetics using second generation sequencing in a Caucasian population. Nature 464, 773-777.

Mukherjee, S., Guha, S., Ikeda, M., Iwata, N., Malhotra, A.K., Pe'er, I., Darvasi, A., Lencz, T., 2014. Excess of homozygosity in the major histocompatibility complex in schizophrenia. Hum. Mol. Genet.

Parham, P., Moffett, A., 2013. Variable NK cell receptors and their MHC class I ligands in immunity, reproduction and human evolution. Nat. Rev. Immunol. $13,133-144$.

Portas, C.M., Goldstein, J.M., Shenton, M.E., Hokama, H.H., Wible, C.G., Fischer, I., Kikinis, R., Donnino, R., Jolesz, F.A., McCarley, R.W., 1998. Volumetric evaluation of the thalamus in schizophrenic male patients using magnetic resonance imaging. Biol. Psychiatry 43, 649-659.

Prugnolle, F., Manica, A., Charpentier, M., Guegan, J.F., Guernier, V., Balloux, F., 2005. Pathogen-driven selection and worldwide HLA class I diversity. Curr. Biol. 15, 1022-1027.

Purcell, S., Neale, B., Todd-Brown, K., Thomas, L., Ferreira, M.A., Bender, D., Maller, J., Sklar, P., de Bakker, P.I., Daly, M.J., Sham, P.C., 2007. PLINK: a tool set for wholegenome association and population-based linkage analyses. Am. J. Hum. Genet. $81,559-575$.

Purcell, S.M., Moran, J.L., Fromer, M., Ruderfer, D., Solovieff, N., Roussos, P., O’Dushlaine, C., Chambert, K., Bergen, S.E., Kahler, A., Duncan, L., Stahl, E., Genovese, G. Fernandez, E. Collins, M.O. Komiyama, N.H. Choudhary, J.S. Magnusson, P.K., Banks, E., Shakir, K., Garimella, K., Fennell, T., DePristo, M., Grant, S.G., Haggarty, S.J., Gabriel, S., Scolnick, E.M., Lander, E.S., Hultman, C.M., Sullivan, P.F., McCarroll, S.A., Sklar, P., 2014. A polygenic burden of rare disruptive mutations in schizophrenia. Nature 506, 185-190.

Qiu, A., Wang, L., Younes, L., Harms, M.P., Ratnanather, J.T., Miller, M.I., Csernansky, J.G., 2009. Neuroanatomical asymmetry patterns in individuals with schizophrenia and their non-psychotic siblings. NeuroImage 47, 1221-1229.

Ramasamy, A., Trabzuni, D., Guelfi, S., Varghese, V., Smith, C., Walker, R., De, T., U.K. Brain Expression Consortium, North American Brain Expression Consortium, Coin, L., de Silva, R., Cookson, M.R., Singleton, A.B., Hardy, J., Ryten, M., Weale, M.E., 2014. Genetic variability in the regulation of gene expression in ten regions of the human brain. Nat. Neurosci. 17, 1418-1428.

Ripke, S., O’Dushlaine, C., Chambert, K., Moran, J.L., Kahler, A.K., Akterin, S., Bergen, S.E., Collins, A.L., Crowley, J.J., Fromer, M., Kim, Y., Lee, S.H., Magnusson, P.K. Sanchez, N., Stahl, E.A., Williams, S., Wray, N.R., Xia, K., Bettella, F., Borglum, A.D., Bulik-Sullivan, B.K., Cormican, P., Craddock, N., de Leeuw, C., Durmishi, N., Gill, M., Golimbet, V., Hamshere, M.L., Holmans, P., Hougaard, D.M., Kendler, K.S., Lin, K., Morris, D.W., Mors, O., Mortensen, P.B., Neale, B.M., O’Neill, F.A., Owen, M.J., Milovancevic, M.P., Posthuma, D., Powell, J., Richards, A.L., Riley, B.P., Ruderfer, D., Rujescu, D., Sigurdsson, E., Silagadze, T., Smit, A.B., Stefansson, H., Steinberg, S., Suvisaari, J., Tosato, S., Verhage, M., Walters, J.T., Multicenter 
Genetic Studies of Schizophrenia, C., Levinson, D.F., Gejman, P.V., Kendler, K.S., Laurent, C., Mowry, B.J., O’Donovan, M.C., Owen, M.J., Pulver, A.E., Riley, B.P., Schwab, S.G., Wildenauer, D.B., Dudbridge, F., Holmans, P., Shi, J., Albus, M., Alexander, M., Campion, D., Cohen, D., Dikeos, D., Duan, J., Eichhammer, P., Godard, S., Hansen, M., Lerer, F.B., Liang, K.Y., Maier, W., Mallet, J., Nertney, D.A., Nestadt, G., Norton, N., O’Neill, F.A., Papadimitriou, G.N., Ribble, R., Sanders, A.R., Silverman, J.M., Walsh, D., Williams, N.M., Wormley, B., Psychosis Endophenotypes International, C., Arranz, M.J., Bakker, S., Bender, S., Bramon, E., Collier, D., Crespo-Facorro, B., Hall, J., Iyegbe, C., Jablensky, A., Kahn, R.S., Kalaydjieva, L., Lawrie, S., Lewis, C.M., Lin, K., Linszen, D.H., Mata, I., McIntosh, A., Murray, R.M., Ophoff, R.A., Powell, J., Rujescu, D., Van Os, J., Walshe, M., Weisbrod, M., Wiersma, D., Wellcome Trust Case Control, C., Donnelly, P., Barroso, I., Blackwell, J.M., Bramon, E., Brown, M.A., Casas, J.P., Corvin, A.P., Deloukas, P., Duncanson, A., Jankowski, J., Markus, H.S., Mathew, C.G., Palmer, C.N., Plomin, R., Rautanen, A., Sawcer, S.J., Trembath, R.C., Viswanathan, A.C., Wood, N.W., Spencer, C.C., Band, G., Bellenguez, C., Freeman, C., Hellenthal, G., Giannoulatou, E., Pirinen, M., Pearson, R.D., Strange, A., Su, Z., Vukcevic, D., Donnelly, P., Langford, C., Hunt, S.E., Edkins, S., Gwilliam, R., Blackburn, H., Bumpstead, S.J., Dronov, S., Gillman, M., Gray, E., Hammond, N., Jayakumar, A., McCann, O.T., Liddle, J., Potter, S.C., Ravindrarajah, R., Ricketts, M., TashakkoriGhanbaria, A., Waller, M.J., Weston, P., Widaa, S., Whittaker, P., Barroso, I., Deloukas, P., Mathew, C.G., Blackwell, J.M., Brown, M.A., Corvin, A.P., McCarthy, M.I., Spencer, C.C., Bramon, E., Corvin, A.P., O’Donovan, M.C., Stefansson, K., Scolnick, E., Purcell, S., McCarroll, S.A., Sklar, P., Hultman, C.M., Sullivan, P.F., 2013. Genome-wide association analysis identifies 13 new risk loci for schizophrenia. Nat. Genet. 45, 1150-1159.

Roussos, P., Haroutunian, V., 2014. Schizophrenia: susceptibility genes and oligodendroglial and myelin related abnormalities. Front. Cell. Neurosci. 8, 5.

Sainz, J., Mata, I., Barrera, J., Perez-Iglesias, R., Varela, I., Arranz, M.J., Rodriguez, M.C., Crespo-Facorro, B., 2013. Inflammatory and immune response genes have significantly altered expression in schizophrenia. Mol. Psychiatry 18, 10561057.

Schizophrenia Psychiatric Genome-Wide Association Study Consortium, 2011. Genome-wide association study identifies five new schizophrenia loci. Nat. Genet. 43, 969-976.

Schizophrenia Working Group of the Psychiatric Genomics, C., 2014. Biological insights from 108 schizophrenia-associated genetic loci. Nature 511, 421-427.

Shatz, C.J., 2009. MHC class I: an unexpected role in neuronal plasticity. Neuron 64, $40-45$.

Shenton, M.E., Whitford, T.J., Kubicki, M., 2010. Structural neuroimaging in schizophrenia: from methods to insights to treatments. Dialogues Clin. Neurosci. 12, 317-332.

Shepherd, A.M., Laurens, K.R., Matheson, S.L., Carr, V.J., Green, M.J., 2012. Systematic meta-review and quality assessment of the structural brain alterations in schizophrenia. Neurosci. Biobehav. Rev. 36, 1342-1356.

Sherman, S., Guillery, R., 2000. Exploring the Thalamus. Academic Press, Imprint.

Shi, J., Levinson, D.F., Duan, J., Sanders, A.R., Zheng, Y., Pe'er, I., Dudbridge, F., Holmans, P.A., Whittemore, A.S., Mowry, B.J., Olincy, A., Amin, F., Cloninger, C.R., Silverman, J.M., Buccola, N.G., Byerley, W.F., Black, D.W., Crowe, R.R., Oksenberg, J.R., Mirel, D.B., Kendler, K.S., Freedman, R., Gejman, P.V., 2009. Common variants on chromosome 6p22.1 are associated with schizophrenia. Nature 460, $753-757$.

Shiina, T., Hosomichi, K., Inoko, H., Kulski, J.K., 2009. The HLA genomic loci map: expression, interaction, diversity and disease. J. Hum. Genet. 54, 15-39.

Sinkus, M.L., Adams, C.E., Logel, J., Freedman, R., Leonard, S., 2013. Expression of immune genes on chromosome 6p21.3-22.1 in schizophrenia. Brain Behav. Immun. 32, 51-62.
Smith, M.J., Wang, L., Cronenwett, W., Mamah, D., Barch, D.M., Csernansky, J.G. 2011. Thalamic morphology in schizophrenia and schizoaffective disorder. J. Psychiatr. Res. 45, 378-385.

Stefansson, H., Ophoff, R.A., Steinberg, S., Andreassen, O.A., Cichon, S., Rujescu, D. Werge, T., Pietilainen, O.P., Mors, O., Mortensen, P.B., Sigurdsson, E., Gustafsson, O., Nyegaard, M., Tuulio-Henriksson, A., Ingason, A., Hansen, T., Suvisaari, J., Lonnqvist, J., Paunio, T., Borglum, A.D., Hartmann, A., Fink-Jensen, A., Nordentoft, M., Hougaard, D., Norgaard-Pedersen, B., Bottcher, Y., Olesen, J., Breuer, R., Moller, H.J., Giegling, I., Rasmussen, H.B., Timm, S., Mattheisen, M. Bitter, I., Rethelyi, J.M., Magnusdottir, B.B., Sigmundsson, T., Olason, P., Masson, G., Gulcher, J.R., Haraldsson, M., Fossdal, R., Thorgeirsson, T.E., Thorsteinsdottir U., Ruggeri, M., Tosato, S., Franke, B., Strengman, E., Kiemeney, L.A., Genetic, R., Outcome in, P., Melle, I., Djurovic, S., Abramova, L., Kaleda, V., Sanjuan, J., de Frutos, R., Bramon, E., Vassos, E., Fraser, G., Ettinger, U., Picchioni, M., Walker, N., Toulopoulou, T., Need, A.C., Ge, D., Yoon, J.L., Shianna, K.V., Freimer, N.B., Cantor, R.M., Murray, R., Kong, A., Golimbet, V., Carracedo, A., Arango, C., Costas, J. Jonsson, E.G., Terenius, L., Agartz, I., Petursson, H., Nothen, M.M., Rietschel, M., Matthews, P.M., Muglia, P., Peltonen, L., St Clair, D., Goldstein, D.B., Stefansson, K., Collier, D.A., 2009. Common variants conferring risk of schizophrenia. Nature $460,744-747$.

Stein, T., Moritz, C., Quigley, M., Cordes, D., Haughton, V., Meyerand, E., 2000 Functional connectivity in the thalamus and hippocampus studied with functional MR imaging. AJNR Am. J. Neuroradiol. 21, 1397-1401.

Stringer, S., Kahn, R.S., Witte, L.D., Ophoff, R.A., Derks, E.M., 2014. Genetic liability for schizophrenia predicts risk of immune disorders. Schizophr. Res.

Traherne, J.A., 2008. Human MHC architecture and evolution: implications for disease association studies. Int. J. Immunogenet. 35, 179-192.

Trowsdale, J., Knight, J.C., 2013. Major histocompatibility complex genomics and human disease. Annu. Rev. Genomics Hum. Genet. 14, 301-323.

Tuoc, T.C., Boretius, S., Sansom, S.N., Pitulescu, M.E., Frahm, J., Livesey, F.J., Stoykova, A., 2013. Chromatin regulation by BAF170 controls cerebral cortical size and thickness. Dev. Cell 25, 256-269.

Veyrieras, J.B., Kudaravalli, S., Kim, S.Y., Dermitzakis, E.T., Gilad, Y., Stephens, M. Pritchard, J.K., 2008. High-resolution mapping of expression-QTLs yields insight into human gene regulation. PLoS Genet. 4, e1000214.

Xie, Q., Yang, Y., Huang, J., Ninkovic, J., Walcher, T., Wolf, L., Vitenzon, A., Zheng, D. Gotz, M., Beebe, D.C., Zavadil, J., Cvekl, A., 2013. Pax6 interactions with chromatin and identification of its novel direct target genes in lens and forebrain. PLoS One 8, e54507.

Yunis, E.J., Larsen, C.E., Fernandez-Vina, M., Awdeh, Z.L., Romero, T., Hansen, J.A., Alper, C.A., 2003. Inheritable variable sizes of DNA stretches in the human MHC: conserved extended haplotypes and their fragments or blocks. Tissue Antigens $62,1-20$.

Zeller, T., Wild, P., Szymczak, S., Rotival, M., Schillert, A., Castagne, R., Maouche, S., Germain, M., Lackner, K., Rossmann, H., Eleftheriadis, M., Sinning, C.R., Schnabel, R.B., Lubos, E., Mennerich, D., Rust, W., Perret, C., Proust, C., Nicaud, V., Loscalzo, J., Hubner, N., Tregouet, D., Munzel, T., Ziegler, A., Tiret, L., Blankenberg, S., Cambien, F., 2010. Genetics and beyond-the transcriptome of human monocytes and disease susceptibility. PLoS One 5, e10693.

Zhang, A., Yu, H., He, Y., Shen, Y., Pan, N., Liu, J., Fu, B., Miao, F., Zhang, J., 2013a. The spatio-temporal expression of MHC class I molecules during human hippocampal formation development. Brain Res. 1529, 26-38.

Zhang, A., Yu, H., Shen, Y., Liu, J., He, Y., Shi, Q., Fu, B., Miao, F., Zhang, J., 2013b. The expression patterns of MHC class I molecules in the developmental human visual system. Neurochem. Res. 38, 273-281. 